\title{
36. DEUTERIUM IN INTERSTITIAL WATERS FROM RED SEA CORES ${ }^{1}$
}

\author{
Irving Friedman and Kenneth Hardcastle, U. S. Geological Survey, Denver, Colorado
}

The deuterium/hydrogen ratio was determined on 49 water samples squeezed from cores collected in the Red Sea by the DSDP Leg 23 expedition. The deuterium/hydrogen ratios, relative to SMOW and given in per mil values, are shown in Table 1 . In order to relate these deuterium measurements to geoligic time, age assignments provided by David A. Ross have been used. Table 1 lists pertinent sample data. The results are also plotted in Figure 1 where the deuterium/hydrogen ratio is shown as a function of the age (in millions of years). It is to be noted that Sites 225 and 227 were drilled close together, and indeed the data from these two sites agree more closely than data from the rest. Data from Site 228, which is located farther south in the Red Sea, have very little relationship to data from the other two sites except that very light (depleted in deuterium) values were found in the older part of the core in the early Pliocene or late Miocene. Site 227 also shows very light values in the late Miocene which are associated with evaporite deposits. Obtaining such light deuterium values would require that the seawater be highly contaminated with fresh water at the sites. This condition might prevail in a very shallow evaporite basin that has some contribution from direct precipitation as well as runoff from the shore. At the end of the Miocene and during early Pliocene the evaporite conditions ceased to exist. At this time the Red Sea must have been opened to the Indian Ocean. This water would be enriched by evaporation in the Red Sea itself and would give deuterium values between 17 and 22. At the end of the Pliocene and beginning of the Pleistocene, the waters in the sediments in Sites 225 and 227 show a decrease in deuterium towards present-day values. This could be the result of raising of sea level and the resulting unrestricted circulation of water. At Site 228 the deuterium values do not show the trend evident at the other two sites. At the end of the Miocene and early Pliocene the deuterium values are still low at Site 228. They rise very slowly through the late Pleistocene. The deuterium results would suggest that Site 228 had a somewhat different hydrologic history than did the hot brine area of Sites 225 and 227.

The results of the deuterium analyses of waters collected during the Atlantis II Station 543 are given in Table 2. It is obvious that the deep Red Sea brines have the same deuterium concentration as does the seawater above. An equally obvious explanation here is that seawater circulates to some depth in open channelways, comes into contact with steam or hot rock, and dissolves material from the evaporite beds that seem to be present in most of the Miocene at this locality.

\footnotetext{
${ }^{1}$ Publication authorized by the Director, U. S. Geological Survey.
}

TABLE 1

Data on Red Sea Sites 225, 227, 228, and 229

\begin{tabular}{ccccc}
\hline Core & Section & $\begin{array}{c}\text { Depth } \\
(\mathrm{m})\end{array}$ & $\begin{array}{c}\text { Time } \\
(\mathrm{m} . \mathrm{y} .)\end{array}$ & $\begin{array}{c}\mathrm{D} / \mathrm{H} \\
(\% \mathrm{oo} \text { SMOW })\end{array}$ \\
\hline
\end{tabular}

Hole 225

$\begin{array}{rrrlr}1 & 6 & 9 & 0.13 & +13.2 \\ 3 & 4 & 23 & 0.34 & 18.4 \\ 5 & 6 & 36 & 0.52 & 20.5 \\ 10 & 2 & 65 & 2.0 & 17.6 \\ 13 & 6 & 86 & 2.4 & 22.4 \\ 16 & 3 & 108 & 2.5 & 21.2 \\ 18 & 4 & 128 & 2.75 & 18.2 \\ 21 & 3 & 153 & 4.2 & 16.7 \\ 23 & 2 & 169 & 5.0 & 14.1 \\ 26 & 1 & 194 & 6.3 & 11.2 \\ 28 & 2 & 215 & 7.0 & 11.5\end{array}$

Hole 227

$\begin{array}{rrrlr}3 & 1 & 27 & 2.1 & +16.6 \\ 5 & 2 & 38 & 2.2 & 17.2 \\ 6 & 2 & 47 & 2.4 & 20.6 \\ 10 & 2 & 74 & 2.6 & 17.1 \\ 12 & 2 & 83 & ? & 18.6 \\ 14 & 1 & 99 & 4.0 & 15.3 \\ 16 & 1 & 113 & 4.2 & 15.1 \\ 18 & 3 & 135 & 4.25 & 13.1 \\ 20 & 3 & 152 & 4.4 & 10.6 \\ 23 & 1 & 158 & 4.5 & 10.0 \\ 25 & 2 & 186 & 4.7 & 10.8 \\ 27 & 1 & 203 & 4.8 & 12.3 \\ 30 & 1 & 226 & 5.0 & 8.9 \\ 36 & 2 & 282 & 5.4 & -1.9 \\ 44 & \mathrm{CC} & 342 & 6.0 & -4.1\end{array}$

Hole 228

$\begin{array}{rcrlr}1 & \text { CC } & 2 & 0.01 & +11.9 \\ 5 & 3 & 37 & 0.25 & 13.3 \\ 7 & 6 & 60 & 0.4 & 13.5 \\ 10 & 3 & 74 & 0.5 & 9.1 \\ 11 & 4 & 84 & 0.6 & 7.3 \\ 13 & \mathrm{CC} & 100 & 0.65 & 5.7 \\ 16 & 5 & 130 & 0.75 & 6.3 \\ 18 & 2 & 144 & 0.8 & 5.1 \\ 21 & 2 & 167 & 2.0 & 3.9 \\ 24 & 3 & 195 & 2.1 & 4.0 \\ 26 & 3 & 214 & 2.15 & 1.4 \\ 28 & 2 & 230 & 2.25 & 1.8 \\ 30 & 4 & 251 & 2.35 & 0.9 \\ 33 & 1 & 268 & 2.4 & -1.1 \\ 35 & 1 & 286 & 2.5 & -0.2 \\ 37 & 2 & 306 & 2.6 & -0.8 \\ \text { Hole } 229 & & & & \\ & & & & \end{array}$


TABLE 1 - Continued

Hole 229A

\begin{tabular}{lrrll}
2 & 6 & 56 & 0.15 & 22.5 \\
$5 \mathrm{~A}$ & 6 & 74 & 0.2 & 18.2 \\
3 & 5 & 100 & 0.25 & 17.1 \\
$9 \mathrm{~A}$ & 2 & 125 & 0.25 & 16.2 \\
$12 \mathrm{~A}$ & 4 & 155 & 0.255 & 16.8 \\
$15 \mathrm{~A}$ & 1 & 176 & 0.30 & 16.3 \\
\hline
\end{tabular}

TABLE 2

Red Sea Hot Brine Atlantis II, Station 543 (Lat $21^{\circ} 20.5^{\prime} \mathrm{N}$, Long $38^{\circ} 03.5^{\prime} \mathrm{E}$ )

\begin{tabular}{rccc}
\hline $\begin{array}{c}\text { Depth } \\
(\mathrm{m})\end{array}$ & $\begin{array}{c}\text { Temperature } \\
\left({ }^{\circ} \mathrm{C}\right)\end{array}$ & $\begin{array}{c}\text { Salinity } \\
\text { (corr-gravimetric) }\end{array}$ & $\begin{array}{c}\mathrm{D} / \mathrm{H} \\
(\% \text { oo SMOW) }\end{array}$ \\
\hline & & & \\
1 & 25.00 & 39.18 & +7.8 \\
49 & 24.63 & 39.34 & +6.6 \\
98 & 23.99 & 39.74 & +4.5 \\
196 & 22.12 & 40.43 & +15.9 \\
492 & 21.71 & 40.54 & +11.2 \\
1675 & 22.00 & 40.59 & +10.2 \\
1957 & 22.11 & 40.66 & +9.8 \\
2016 & 55.94 & 257 & +6.6 \\
2045 & 55.92 & 258 & +6.2 \\
2065 & 55.92 & 257 & +8.2 \\
2094 & 55.90 & 257 & +9.1 \\
2103 & 55.92 & 256 & +8.5 \\
\hline
\end{tabular}

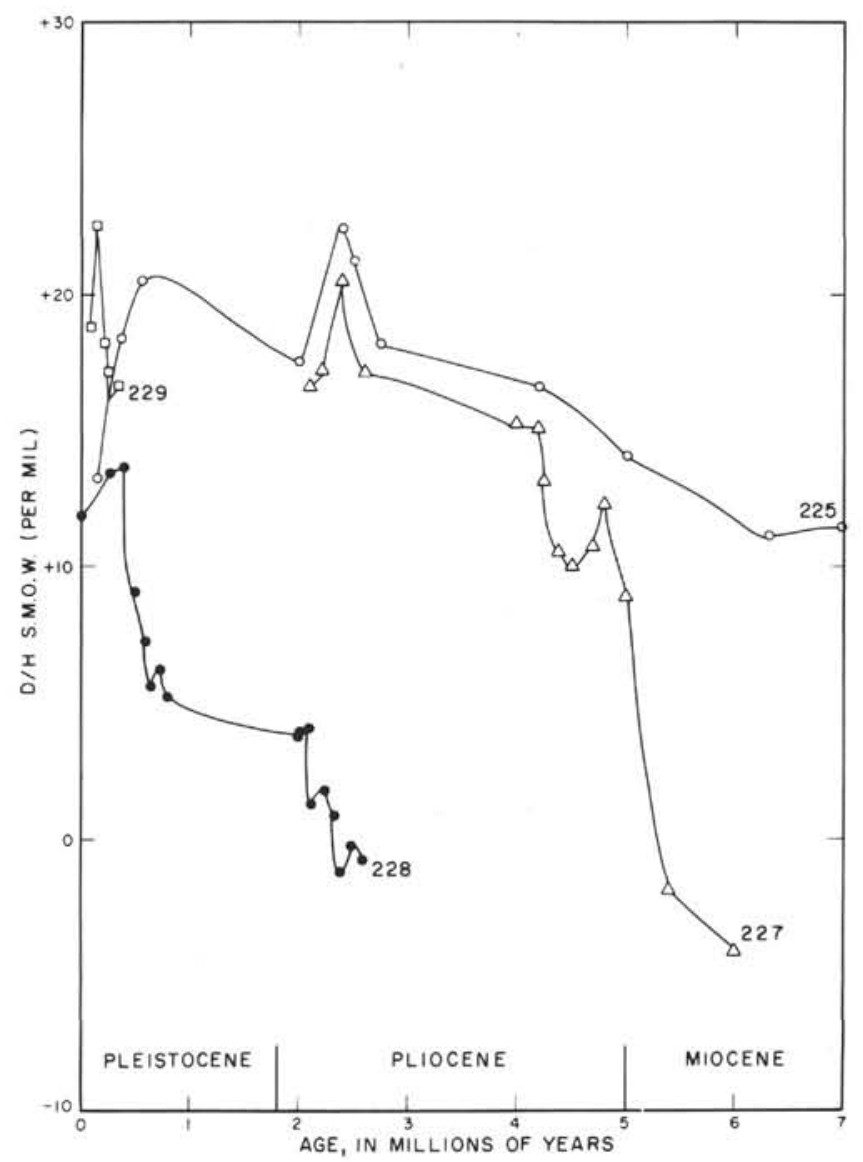

Figure 1. Deuterium/hydrogen in pore fluids versus age of sampled horizon. 